\title{
A state of art review on optimization techniques in just in time
}

\author{
Ineen Sultana and Imtiaz Ahmed*
}

Department of Industrial and Production Engineering, Bangladesh University of Engineering and Technology (BUET), Dhaka -1000, Bangladesh

\section{H R O N I C L E}

Article history:

Received June 10, 2013

Received in revised format

25 August 2013

Accepted October 232013

Available online

October 242013

Keywords:

Just in Time

Kanban

CONWIP

\section{A B S T R A C T}

\begin{abstract}
With the development of faster means of communication, better quality computers and rapid transportation systems, manufacturing is no longer restricted at local level, but has become global in character. As a manufacturing company has to become competitive for its survival, it has to supply products of consistent high quality at reliable and reduced delivery time. Market also demands more product variants that means reduced lot size and high flexibility in operations. Manpower cost has also risen. All these factors tend to increase the product cost. However, the industry has to maintain the cost at a reasonable level. Confronting these challenges, companies world-wide are forced to find ways to reduce costs, improve quality, and meet the ever-changing needs of their customers. One successful solution has been the adoption of Just-in-time (JIT) manufacturing strategy in which many functional areas of a company such as manufacturing, engineering, marketing, purchasing etc. are involved. In this paper, literature review on research works based on JIT was carried out and presented. The introductory section deals with the philosophy of JIT, and the concept involved in Kanban optimization and later this paper reviews literature on optimization Technique in JIT implementation.
\end{abstract}

(C) 2014 Growing Science Ltd. All rights reserved.

\section{Introduction}

JIT may be perceived as an operations management philosophy geared towards the eventual elimination of all kinds of waste in an organization. The two operating goals of striving to achieve zero defects and zero stocks at all stages of production are reflections of waste eliminations, since inferior quality and stocks are considered to be the root of all evil, concealing the inefficiencies in material, machine, manpower, money, information and time utilizations. JIT- based practices cover a broad range of managerial and operational functions. These include human resources management, plant layout, engineering design, purchasing, stock control, scheduling, quality assurance, set-up; maintenance planning and demand management. JIT may be described as an extension of the original concept of managing the material flow in a factory to reduce the inventory levels. In fact, there is much more involved in a manufacturing organization than reducing inventories to control costs. Manufacturing has to deal with other issues, such as process control, level of automation, flexible manufacturing, machine set up times, direct labor productivity, Overhead, supplier management, engineering support, and the quality of product delivered to customers. A modern manufacturing

* Corresponding author.

E-mail addresses: imtiaz_avi@yahoo.com (I. Ahmed) 
Organization has to deal efficiently with these issues in order to operate a smooth, productive, and quality minded department.

There is reasonable consensus among researchers that JIT is a philosophy of continuous improvement in which non-value adding activities are identified and removed in order to reduce costs, improve product quality, improve performance, improve delivery, add manufacturing flexibility and stimulate innovation in the workplace. Numerous organizations have reported cost cutting and improved quality due to JIT practices. JIT was a technology that permitted many firms to compete successfully in the face of growing competition. Continuous monitoring of production processes with the goal of eliminating all forms of waste is a key point in understanding JIT. Advocates of JIT view inventory as a waste and a source of all evils because inventory build-ups tend to hide production problems rather than solve them. JIT provides authorization for single parts that arrive just in time to be consumed, resulting in stockless production and significant cost savings. Research has shown that JIT organizational philosophy has the potential to increase organizational efficiency and effectiveness. On the other hand, if JIT is not properly implemented, desirable benefits are not realized. In theory, it is easy to understand the concepts of JIT in terms of eliminating waste and improving productivity. However, in reality, the concepts are difficult to implement because of the need for fundamental organizational changes.

When JIT principles are implemented successfully across many parts of an organization, a significant competitive advantage can be enjoyed. The JIT benefits do not just happen. Before an organization enjoys the fruits of JIT, it must accept JIT as an organizational philosophy. This requires the organization to change or modify its operating procedures, production system and organizational culture. Plant layouts have to be adjusted, relationships with suppliers and customers have to be modified, quality circles have to be installed and accurate demand forecasts have to be achieved.

The objectives of this paper are as listed below:

1) Critical review of JIT literature,

2) Segregating the different research articles of JIT,

3) Exploring the recent trends in JIT-Kanban system and deriving directions for future research.

In this paper, different articles are reviewed and an appropriate classification is presented. The Kanban study was made elaborately, since it acts as a basic communicator and feed-back agent to the JIT system. The latest trends in JIT-Kanban system are also addressed separately under the heading "Special cases". Finally, the directions for future researches are presented. This paper addresses the literature review on implementation of Just in time philosophy specially Kanban optimization with empirical study, mathematical modeling, simulation of various algorithm in this field. Besides extensive work on JIT in supply chain system and the variability and its effect are also analyzed. The paper is organized according to the study and model used in JIT implementation. Section 2 presents an integrated approach to JIT philosophy and a brief concept about Kanban optimization. Section 3 to 8 summarizes the major works in JIT field according to categorization and some special cases are highlighted at the section 9. In section 10 some general insights and future research directions are discussed.

\section{An integrated approach to JIT philosophy}

JIT has become somewhat of a catchphrase in recent times with heavy overlaps to concepts such as TQM, continuous improvement, time-based manufacturing, and business process re-engineering. Although most academics and practitioners agree that JIT consists of a set of techniques such as Kanban, JIT purchasing, TQM, line balancing, setup time elimination plans, supplier integration, 
level schedules, integrated product and process design, total productive and preventive maintenance, group technology, focused factory, multifunction employee and employee training, no universal set of elements has been established to optimize system performance. A major constraint to JIT implementation is that there are no universally accepted JIT techniques, as they seem to vary from culture to culture and from industry to industry. Voss and Robinson (1987) observed that where manufacturing practitioners attempt to implement JIT, most of them select just a subset of JIT techniques, suggesting that companies focus on easy to implement techniques rather than those giving the greatest benefits.

JIT has been described as a comprehensive production and inventory control system. However, various past researchers fail to incorporate quality improvement and employee involvement activities as integral parts of JIT philosophy. Flynn et al. (1995) proposed that the use of TQM practices would enhance JIT performance through process variance reduction and improve quality performance through problem exposure. Fullerton (2003) observed that JIT firms significantly use more TQM tools to evaluate performance than non-JIT firms. Most studies on JIT philosophy tend to investigate these practices separately. When a manufacturing plant seeks to capitalize on the implementation of one of these streams, the benefits can be maximized by also applying techniques of the other two streams. Therefore, there should be a synergistic effect of integrating unique JIT techniques with TQM and human/ strategic oriented JIT practices. Many studies have suggested that JIT, TQM, and human resource management are interrelated and are internally consistent practices. Altogether, the unique JIT techniques, TQM, and human/strategic- related JIT methods form a comprehensive and consistent set of JIT practices, which will generate excellent performance.

Several scholarly journals in the last decade have published a number of articles focusing on the implementation of JIT techniques and their performance in both JIT and non-JIT manufacturing plants. In both studies, they focused on implementation differences between small and large American manufacturers using ten management practices supposedly constituting the JIT concept. Brox and Fader (2002) assessed the impact of JIT based on economic theory and the impact of JIT management strategies on plant level productivity applying variable cost function estimates. Empirical research so far involving the study of JIT consists primarily of case studies of specific organizations, which have implemented JIT, and more recently have described simulations and mathematical modeling. Modeling of JIT generally focuses on relationships between changes in various production factors and the corresponding specific production performance measures.

To implement the Just-In-Time (JIT) idea in production, logistics or supply chain systems efficient control mechanisms are necessary. In that context Kanban is one of the broadest investigated control mechanisms. The existing literature to Kanban systems is very voluminous, for a comprehensive treatise. The investigated systems differ one another in regard to the assumptions made and in regard to the goals investigated.

A Kanban system operates only with single card is called production order Kanban (POK) (J. Berkley, 1992; Sarathapreeyadarshini et al., 1997). If the distance between the consecutive workstations is very short, a single buffer mode is made available between the workstations. This buffer mode acts as both outbound buffer for the current workstation $\mathrm{j}$ and inbound buffer for the succeeding workstation $\mathrm{j}+1$, respectively. In the two-card system, where the distance between the two consecutive work stations are more, each work station will have separate inbound buffer and outbound buffer (Kimura et al., 1981; Hemamalini, et al., 2000) and the cards are called as Production Order Kanban (POK) and Withdrawal Kanban(WK), respectively.

The two-card Kanban pull system which works in the Assembly/Manufacturing line is elaborated by Panneerselvam (1999), Kimura and Terada (1981) and Hemamalini et al. (2000). Basically, it has plastic cards, which give information about the parts and also things to be done. The production 
order Kanban (POK) is a production order, which instructs the preceding work- station to produce the required number of units. The withdrawal Kanban (WK) gives the message to the succeeding process about the number of units it should withdraw.

\section{Introductory Early Works}

The first article on the JIT implementation in manufacturing appeared in the 1970s (Sugimori et al., 1977). Since then, hundreds of JIT papers have been published in professional journals. This body of literature describes the JIT philosophy and its implementation in manufacturing. It contains conceptual and empirical studies, simulation and mathematical models, as well as case studies. Two general review articles have attempted to integrate the reported research in this field (Sohal et al., 1989). However, these reviews cite only a limited number of refereed journal publications and do not provide a framework for classifying the JIT literature. The reviews also fail to link critical variables with the basic tenets of the JIT philosophy (i.e. elimination of waste, employee involvement in decision-making, supplier participation and total quality control). Two topic-specific reviews have been published on cellular manufacturing (Huang \& Houck, 1985) and worker cross-training (Treleven, 1989). Because of their narrow topical focus, these review articles do not integrate the developments in these fields with overall JIT implementation.

Golhar et al. (1991) have classified the JIT literature as elimination of waste, employee participation, supplier participation and total quality control. A similar work was done by Berkly (1992) for Kanban production process. He has selected 24 elements in the Kanban production system as operational design factors. Obviously, most of the researchers were focusing on the determination of number of Kanbans and determining corresponding solutions by using suitable models and tools. Some authors have developed simulations model and meta-heuristics like, genetic algorithm (GA), tabu search (TS), and simulated annealing (SA) for JIT-Kanban for better solutions. Further, more researches have been done in empirical theory, flow shop, simulation, variability and its effects, CONWIP and special cases.

\section{Empirical theory}

Empirical studies on JIT implementation in manufacturing have been done more recently. These studies typically used a small sample size, are industry specific or collected data from the JIT companies in a particular geographic location. Nonetheless, they examine the effectiveness of the JIT implementation. A major focus of these studies has been on the benefits and the problems of JIT implementation. However, JIT implementation involves additional costs to provide new equipment and the employee training programmes (Finch, 1986). Although benefits and costs have been discussed separately in the literature, no empirical studies have been undertaken to examine the cost effectiveness of the JIT implementation. In the paper by Monden (1983), a comprehensive presentation of Toyota production system is given. A successful kanban system will drastically reduce the throughput time and lead time Philipoom et al. (1987). Karmarker and Kekre (1989) concluded from their studies that the reduction in container size and increase in number of Kanbans lead to better results. Many researchers were interested in finding the optimal number of Kanbans. The Toyota formula is very much useful in determining the optimal number of Kanbans. Co Henry et al. (1987) used the Toyota formula and also investigated the safety stock allocations in an uncertain dynamic environment. A similar work was considered by Sarkar et al. (1996) to find number of Kanbans between two adjacent workstations. Yale et al. (2000) presented a study for Kanban system, CONWIP and buffered production lines. In this study, they incorporated a non-integral approach using simulation. The use of non-integral approach helps production planners to obtain discrete number of Kanbans. Woolsey et al. (1999) have developed a simple spreadsheet optimization program to determine the corresponding number of Kanbans with respect to user-defined safety stock levels and other values. It gives a close-form of solution to the problem. This means that an answer 
for any problem size may be instantaneously obtained.

Kanban system is widely implemented in repetitive manufacturing environment. For a single card operational system, Saradhapriyadarshini et al. (1997) have developed two heuristics and proved that these are more efficient. Saradhapriyadarshini et al. (1997) have proposed a recursive equation for scheduling the single card Kanban system with dual blocking. They proposed a heuristic with twin objectives of minimizing the sum of total weighted time of containers and weighted flow time of parttypes. Rajendran (1999) has done a work on two card flow shop scheduling with n part-types. In this paper, mathematical models for time tabling of containers for different problems have been formulated. Then, a heuristic was developed to minimize the sum of weighted flow time, weighted earliness, and weighted tardiness of containers. Hemamalini et al. (2000) have done similar work. In this work, the heuristic developed is simulated annealing algorithm. This is compared with random search method. In these papers, the comparisons are done only based on mean relative percentage increase. Instead of this approach, comparisons based on complete ANOVA experiment would provide reliable inference. Brucker et al. (2003) have carried out research on flow shop problem with a buffer of limited capacity between two adjacent machines. After finishing the processing of a job on a machine, either the job is to be processed on the following machine or it is to be stored in the buffer between these machines. If the buffer is completely occupied, the job has to wait on its current machine but blocks this machine for other jobs. In this paper, they determined a feasible schedule to minimize the make span using tabu search. The results of the problem using tabu search were compared with that of benchmark instances. The comparisons are done only based on relative improvements. Instead of this approach, comparisons based on complete ANOVA experiments would provide reliable inference.

Assembly lines are similar to the flow shops in which assembly of parts are carried out in a line sequence. In a multi product assembly line, the sequencing of the jobs is a challenging task. Drexl Kimms (2001) considered an assembly line sequencing mixed model problem. It is a combinatorial problem. They formulated this combinational problem as integer programming model. This model can be used only for small size problems due to the limitations of operations research software with respect to handling the number of variables and constraints, which are present in the integerprogramming model. Xiaobo and Ohno (1997) have considered similar work on mixed model assembly line sequencing problem with conveyor stoppages. They proposed branch and bound algorithm, and simulated annealing algorithm for finding the optimal solution and sub-optimal solution of the mixed-model sequencing problem, respectively to minimize the total conveyor stoppage time. The branch- and-bound method was devoted to find the optimal solution of smallsized problems, whereas the simulated annealing method was used to cope with large-scale problems to obtain a good sub-optimal solution. Future, research on simulated annealing applied to this problem can be directed to establish a better seed generation algorithm. However, the practitioner should spend considerable time in fixing the parameter called temperature $(\mathrm{T})$ in the simulated annealing algorithm by trial and error method before actually solving the problem.

In a batch production system, the switching over from one product to other product depends on many factors such as stock reaching to the threshold level, different priority schemes, economical setups, etc. Tayfur and Goang (2000) have dealt this issue differently for the pull type manufacturing system with multi product types. In this paper, they developed an iterative procedure to approximately compute the average inventory level of each product as finished goods using different priority schemes. In this paper, the demand arrival process is assumed to be a Poisson distribution and processing times and the set-up times are arbitrarily distributed. But, in practice, the processing times may follow other distributions, viz., normal, uniform, exponential, etc. which are not experimented in this paper. Khan and Sarker (2002) addressed the problem of manufacturing system that procures raw materials from vendors in lot and convert them into finished products. They 
estimated production batch sizes for JIT delivery system and designed a JIT raw material supply system. A simple algorithm was developed to compute the batch sizes for both manufacturing and raw material purchasing policies.

\section{Modeling approach}

Modeling approach aims to obtain the optimal solution. This subsection reviews different modeling approaches. Kimera and Terada (1981) have developed a mathematical model in the area of Kanban system. They have given a basic balance equation for multi stage systems, which shows how the fluctuation of final demand influences the fluctuation of production and inventory volumes. Bitran and Chang (1987) have designed an optimization model for the Kanban system. The model is intended for a deterministic multi-stage capacitated assembly-type production setting. In this paper, a non-linear model developed by them is converted into a linear model with deterministic demand. Seki et al. (1999) have designed a single stage Kanban system with poison demand arrivals. The system is formulated as a queuing system under piecewise constant load, and a numerical method by transient solutions of the queue is applied. Yoichi Seki et al. (1999) did similar work on the single stage Kanban system with poison demand and Erlang production times. The objective of this work is to determine the number of Kanbans, when a change of load to the system is planned. Vito Albino et al. (1995) studied a model of Kanban controlled manufacturing system based on Markovian assumption. An approximate approach was developed to solve the model, which permits reliable evaluation of performance in terms of throughput time and work-in-process (WIP). Further, they validated the results using discrete-event simulation applied to their problem. Nori and Sarkar (1998) have modeled the Kanban system using Markov-chain to determine the optimum number of Kanbans between adjacent workstations. Deleersnyder et al. (1989) have modeled a blocking situation in the queues of the Kanban system using discrete time Markovian chain to study the effect of number of Kanbans, machine reliability, processing time and demand variability. Markham et al. (1998) formed a procedure based rule induction approach for determining the number of Kanbans and other factors in JIT. They applied classification and regression tree (CART) technique to generate the production rule, based on decision trees. As for as designing of Kanban system, a basic simulation study was done by Davis et al. (1987) to determine the number of Kanbans. In another work by Rudi De Smet et al. (1998) a simulation model was developed to study the feasibility of plans to produce some subparts of the product in a Kanban-controlled manner to determine the operational parameters such as number of Kanbans and container size. In a kanban control system, the main decision parameters are the number of Kanbans and lot size. Alabas et al. (2002) developed three-meta heuristics viz., genetic algorithm (GA), simulated annealing (SA) and tabu search (TS) coupled with a simulation model to find the optimum number of Kanbans with the minimum cost. In addition, a neural network meta model was developed and compared with the heuristic procedures in terms of solution accuracy. They found that the tabu search requires less computational efforts when compared to the other two meta-heuristics and the neural network meta-model. In a similar work by Hurrion R.D. (1997), simulation and neural network meta- model have been used for designing the Kanban system. Ohno et al. (1995) proposed an algorithm to determine the optimal number of Kanbans for each of the two kinds of Kanban (production ordering and supplier Kanbans) under stochastic demand. An algorithm was devised for deter- mining the optimal number of Kanbans that minimizes the expected average cost per period. Since, no safety stock is assumed in this paper, this can be regarded as a procedure for determining the safety stock also. Sarkar et al. (1999) studied a multi-stage Kanban system for short life-cycle product in the market. In this research, the problem is to find optimally the number of orders for raw-materials, Kanbans circulated between workstations, finished goods shipments to the buyers, and the batch size for each shipment (lot) with minimum total cost of the inventory. A cost function was developed based on the costs incurred for the raw materials, the work-in-process and the finished goods. The optimal number of raw material orders that minimizes the total cost is obtained first, which is then used to find the minimum number of Kanbans, finished goods shipments, and the batch sizes of shipments. 


\section{Variability and its effects}

Savsar and Al-Javini (1995) studied a simulation model to investigate the effect of different operational conditions, including Kanban withdrawal policies on three performance measures of JIT, viz., average throughput rate, average station utilization and average work-in-process. Unlike other simulation studies that use exponential or truncated normal distribution, this model uses Erlang and Gama distribution. It is observed that the throughput rate as well as the average station utilization is significantly affected by the variability in processing time and demand intervals. They proposed two types of Kanban withdrawal cycles, namely fixed withdrawal policy and variable withdrawal policy. Under the fixed withdrawal policy, the time interval between consecutive visits of a partcarrier to a workstation for kanban removal is fixed, but the order quantity (number of Kanbans carried) is variable whereas under the variable withdrawal policy, the time interval between consecutive visits of a part-carrier to a workstation for Kanban removal is variable, but the order quantity is fixed. Huang et al. (1983) have found that overtime required will be increased when the variation in processing time is increased. Also, they emphasized that a Kanban system would not be effective with high variable processing or set up time. Villeda et al. (1988) performed simulation study for a final assembly consisting of " 3 sub-assembly lines and 4 stages" repetitive production systems with Kanbans. They concluded that improved productivity obtained through unbalancing the processing time at all workstations increases directly with the variability in the final assembly. Chaturvedi and Golher (1992) simulated a Kanban based flow production line for a product in nine sequentially arranged workstations. They observed that the system performance was worst for exponential processing time distribution and variability affected station utilization, throughput time and WIP inventory. Yavuz and Satir (1995) have studied the simulation of multi-item, multi-stage flow line operating under the JIT philosophy with a two-card Kanban technique. The flow line produces four products through five stations. This study uses partial factorial design for experimentation. Seven experimental clusters are designed, each composed of at most three factors. The $F$ ratios and the degrees of freedom of the model are obtained from multi variate analysis of variance (MANOVA). They found that decrease in lot size reduces mean length and waiting times in work-in-process points at all Kanbans levels. An increase in the uncertainty of demand arrival rates and demand sizes increases the probability of sudden over- loading. An increase in the coefficient of variation in processing times brings about higher line utilization and a decrease in throughput rate. The scheduling rules tested in this paper are found to yield no significant differences in the utilization of line and on the behaviors of work-in- process. Feeder lines may be introduced into the pull system configuration, where lines feed the final assembly line. Further, alternate operating routes for the products along the line may be introduced.

\section{CONWIP}

CONWIP is a Kanban system working with constant work- in-process. CONWIP is a generalized form of Kanban. Like, Kanban system, it relies on signals, which could be electronic and it is equivalent to kanban cards. In a CONWIP system, the cards traverse a circuit that includes the entire production line. A card is attached to a standard container of parts at the beginning of the line. When the container is used at the end of the line, the card is removed and sent back to the beginning of the line where it waits in a card queue to eventually be attached to another container of parts. Oscar Rubiane et al. (2003) have reviewed the literatures and presented the benefits and comparison of the CONWIP systems. Most of the articles reveal that the CONWIP system works more efficiently than the conventional Kanban systems. Yang (2000) compared 3 different systems viz., Single Kanban, Dual Kanban and CONWIP. The results show that CONWIP consistently produces the shortest mean customer waiting time and lowest total work-in-process. Spearman et al. (1990) have stressed that the flexibility of CONWIP system allows it to be used by any product-line where the utility of Kanban system is limited. Hence, the superiority of CONWIP pull system is an alternative to Kanban system. They present theoretical arguments and simulation study of CONWIP. 


\section{Supply Chain System}

There are number of articles in Supply Chain Management (SCM). In this present survey, a few JITSCM related articles are reviewed. In pull production management systems such as JIT, deliveries must be made on an as-needed basis only, and production begins only when requested. It is supposed to match customer demand that is, producing only enough to replenish what the customer has used or sold. Vergara et al. (2002) have dealt the co- ordination between different parts of simple supply chain. Materials should be moved from one supplier to other supplier as per the JIT. For this, an evolutionary algorithm was used which identifies the optimal or near optimal, synchronized delivery cycle time and suppliers' component sequences for a multi-supplier, multi-component simple supply chain. The evolutionary algorithm also calculates a synchronized delivery cycle time for the entire supply chain, the cumulative cost throughout the supply chain, and the cost to each supplier. The results of this algorithm were compared with enumeration method and found that the evolutionary algorithm gives better solution in quick manner. Minner (2003) did a comprehensive review of multiple-supplier inventory models in supply chain management. SCM discusses strategic aspects of supplier competition, operation flexibility, global sourcing and inventory models. Further it was extended to logistics and multi echelon system. Matheo et al. (2003) have carried out a case study on inventory management in a multi-echelon spare parts supply chain. This paper clearly shows the close relationship between supply chain structure and demand patterns. The problems of managing supply chain with various numbers of echelons, multi model, extremely variable demand and lack of visibility over the distribution channel are discussed. They provided an algorithmic solution through the comprehension of the sources of demand variability and through a probabilistic forecast and inventory management. David and Eben Chaime (2003) have enumerated the vendor-buyer inventory production models. They argue that there should be a certain degree of independence between successive links of the supply chain, to allow flexibility in production management in individual links. They identified the degree of independence and level of flexibility in terms of lot sizing and delivery scheduling in a single-vendor-single-buyer system. In these lines, appropriate two-sided vendor-buyer inventory production models are formulated and analyzed.

\section{Special cases}

Krieg et al. (2002) considered a Kanban controlled production system with 3 or more different products processed on a single manufacturing facility as a decomposed system. The customers for a product arrive as per poison distribution. The service time and set-up changes are product specific and follow exponential distribution. If the customer's demand cannot be met from stock, the customer leaves and satisfies his demand elsewhere (lost sales). The production run continues until the target inventory level given by the Kanbans for the product has been reached. Then the manufacturing facility is set-up for producing the next product. Takashashi et al. (2002) have proposed a decentralized reactive Kanban system for multi-stage production and transportation system with unstable changes in product demand. In the proposed system, the time series data of the demand from the succeeding stage are monitored at each stage individually and unstable changes in the demand are detected by utilizing control charts. In order to develop a control rule of the buffer size, the multistage production and transportation system is decomposed into single-stage processing systems and the performance of the decomposed system is investigated by simulation experiments under various stable-demand conditions. The performance of this system shows superior result. The work of Tardif et al. (2001) introduces a new adaptive Kanban-type pull control mechanism, which determines the timings to release or reorder raw parts based on customer demands and inventory back orders. In the adaptive pull system, the number of Kanbans in the system is dynamically readjusted based on current inventory level and backorder level. Unlike a conventional system, this system absorbs extra Kanbans according to the variability in demand. It was found from the results of a simulation study of a single- stage, single product Kanban system that these systems are beneficial in production line under variable demand conditions. It shows that this adaptive system under such conditions 
outperforms the traditional Kanban pull control mechanism. This adaptive approach may be extended for multi-stage, multi-product Kanban system. SO (1997) presents the buffer allocation problem with the objective of minimizing the average work-in-process subject to minimum required throughput rate and constraint on the total buffer space availability. Both the balanced and unbalanced lines were considered in this work. On the basis of empirical results, he developed a good heuristic for selecting the optimal buffer allocations. The mathematical model discussed in this paper is based on the two assumptions that there are always materials available for processing at the beginning of the line and that the last station can never be blocked. Lai et al. (2003) have proposed a system dynamic (SD) methodology for studying the new generation of JIT in electronic commerce environment. It is a framework for thinking about how the operating policies of a company and its customers, competitors and suppliers interact to shape the company's performance over time.

\section{Conclusion}

The growing global competition forces many companies to reduce the costs of their inputs so that the companies can have greater profit margin. There are considerable advancements in technology and solution procedures in reality, to achieve the goal of minimizing the costs of inputs. JIT-KANBAN is an important system, which is used in production lines of many industries to minimize work-inprocess and throughput time, and maximize line efficiency. In this paper, the authors have made an attempt to review the state of-art of the research articles in the area "JIT-Kanban system". After a brief introduction to push and pull systems, different types of Kanban and their operating principles, blocking mechanisms, the authors have classified the research articles under JIT-Kanban system into five major headings, viz., empirical theory, modeling approach, variability and its effect, CONWIP and JIT-SCM. Also, the authors have provided a section for special cases under JIT-Kanban. This paper would help the researchers to update themselves about the current directions and different issues under JIT-Kanban system, which would further guide them for their future researches.

This paper has summarized the research works, which have been done in Just in Time arena for the last 35 years. These research outcomes are analyzed and separated based on the basic approach used for implementation. Further research can be done on the improvement of the solution accuracy of the heuristics or various algorithms used in the current solution practice. Ants colony optimization algorithm is a recent inclusion to the existing meta-heuristics viz., simulated annealing algorithm, genetic algorithm and tabu search. Therefore, a researcher can study the solution accuracy as well as required computational time of this algorithm for his/her JIT problem of interest.

\section{References}

Alabas, C., Altiparmak, F., \& Dengiz, B. (2002). A comparison of the performance of artificial intelligence techniques for optimizing the number of Kanbans. Journal of the Operational Research Society, 53(8), 907-914.

Albino, V., Dassisti, M., \& O Okogbaa, G. (1995). Approximation approach for the performance analysis of production lines under a kanban discipline. International journal of production economics, 40(2), 197-207.

Bitran, G. R., \& Chang, L. (1987). A mathematical programming approach to a deterministic kanban system. Management Science, 33(4), 427-441.

Berkley, B. J. (1992). A review of the kanban production control research literature. Production and Operations Management, 1(4), 393-411.

Brox, J. A., \& Fader, C. (2002). The set of just-in-time management strategies: an assessment of their impact on plant-level productivity and input-factor substitutability using variable cost function estimates. International Journal of Production Research, 40(12), 2705-2720.

Brucker, P., Heitmann, S., \& Hurink, J. (2003). Flow-shop problems with intermediate buffers. OR 
Spectrum, 25(4), 549-574.

Co Henry, C., \& Sharafali, M. (1997). Overlapping factor in Toyota's formula for computing the number of Kanbans. IIE Trans, 29(5), 409-415.

David, I., \& Eben-Chaime, M. (2003). How far should JIT vendor-buyer relationships go?. International Journal of Production Economics, 81, 361-368.

Davis, W. J., \& STUBITZ, S. J. (1987). Configuring a kanban system using a discrete optimization of multiple stochastic responses. International Journal of Production Research, 25(5), 721-740.

De Smet, R., \& Gelders, L. (1998). Using simulation to evaluate the introduction of a Kanban subsystem within an MRP-controlled manufacturing environment.International journal of production economics, 56, 111-122.

Deleersnyder, J. L., Hodgson, T. J., Muller-Malek, H., \& O'Grady, P. J. (1989). Kanban controlled pull systems: an analytic approach. Management Science,35(9), 1079-1091.

Drexl, A., \& Kimms, A. (2001). Sequencing JIT mixed-model assembly lines under station-load and part-usage constraints. Management Science, 47(3), 480-491.

Finch, B. (1986). Japanese management techniques in small manufacturing companies: a strategy for implementation. Production and inventory management, 27(3), 30-38.

Flynn, B. B., Sakakibara, S., \& Schroeder, R. G. (1995). Relationship between JIT and TQM: practices and performance. Academy of management Journal,38(5), 1325-1360.

Fullerton, R. R., \& McWatters, C. S. (2002). The role of performance measures and incentive systems in relation to the degree of JIT implementation. Accounting, Organizations and Society, 27(8), 711-735.

Golhar, D. Y., \& Stamm, C. L. (1991). The just-in-time philosophy: a literature review. The International Journal of Production Research, 29(4), 657-676.

Hemamalini, B., \& Rajendran, C. (2000). Determination of the number of containers, production Kanbans and withdrawal Kanbans; and scheduling in kanban flowshops-Part 2. International Journal of Production Research, 38(11), 2549-2572.

Herer, Y. T., \& Shalom, L. (2000). The Kanban assignment problem-A non-integral approach. European Journal of Operational Research, 120(2), 260-276.

Huang, P. Y., \& Houck, B. L.W. (1985). Cellular manufacturing: An overview and bibliography. Production and Inventory Management, 26, 83-93

Huang, P. Y., Rees, L. P., \& Taylor, B. W. (1983) A simulation analysis of Japanese Just In Time technique with Kanban for multi line multi stage production system. Decision Sciences, 14(3), 326-344.

Hurrion, R. D. (1997). An example of simulation optimisation using a neural network metamodel: finding the optimum number of Kanbans in a manufacturing system. Journal of the Operational Research Society, 48(11), 1105-1112.

Karmarkar, U. S., \& Kekre, S. (1989). Batching policy in kanban systems. Journal of Manufacturing Systems, 8(4), 317-328.

Khan, L. R., \& Sarker, R. A. (2002). An optimal batch size for a JIT manufacturing system. Computers \& Industrial Engineering, 42(2), 127-136.

Kimura, O., \& Terada, H. (1981). Desiǵn and analysis of Pull System, a method of multi-staǵe production control. The International Journal Of Production Research, 19(3), 241-253.

Krieg, G. N., \& Kuhn, H. (2002). A decomposition method for multi-product kanban systems with setup times and lost sales. IIE Transactions, 34(7), 613-625.

Lai, C. L., Lee, W. B., \& Ip, W. H. (2003). A study of system dynamics in just-in-time logistics. Journal of Materials Processing Technology, 138(1), 265-269.

Markham, I. S., Mathieu, R. G., \& Wray, B. A. (1998). A rule induction approach for determining the number of Kanbans in a just-in-time production system. Computers \& industrial engineering, 34(4), 717-727.

Minner, S. (2003). Multiple-supplier inventory models in supply chain management: A review. International Journal of Production Economics, 81, 265-279.

Monden, Y. (1983). Toyota production system: practical approach to production management (pp. 
p-59). Norcross, GA: Industrial Engineering and Management Press, Institute of Industrial Engineers.

Nori, V. S., \& Sarker, B. R. (1998). Optimum number of Kanbans between two adjacent stations. Production Planning \& Control, 9(1), 60-65.

Ohno, K., Nakashima, K., \& Kojima, M. (1995). Optimal numbers of two kinds of Kanbans in a JIT production system. International Journal of Production Research, 33(5), 1387-1401

Ovalle, O. R., \& Marquez, A. C. (2003). Exploring the utilization of a CONWIP system for supply chain management. A comparison with fully integrated supply chains. International Journal of Production Economics, 83(2), 195-215.

Panneerselvam, R. (2012). Production and operations management. PHI Learning Pvt. Ltd..

Philipoom, P. R., Rees, L. P., TAYLOR III, B. W., \& Huang, P. Y. (1987). An investigation of the factors influencing the number of Kanbans required in the implementation of the JIT technique with Kanbans. International Journal of Production Research, 25(3), 457-472.

Rajendran, C. (1999). Formations and heuristics for scheduling in kanban flow shop to minimize the sum of weighted flowtime, weighted tardiness and weighted earliness of containers. International Journal of Production Research, 37(5), 1137-1158

Sarker, B. R., \& Balan, C. V. (1996). Operations planning for Kanbans between two adjacent workstations. Computers \& industrial engineering, 31(1), 221-224.

Sarker, B. R., \& Balan, C. V. (1999). Operations planning for a multi-stage kanban system. European Journal of Operational Research, 112(2), 284-303.

Savsar, M., \& Al-Jawini, A. (1995). Simulation analysis of just-in-time production systems. International Journal of Production Economics, 42(1), 67-78.

Sharadapriyadarshini, B., \& Rajendran, C. (1997). Heuristics for scheduling in a Kanban system with dual blocking mechanisms. European journal of operational research, 103(3), 439-452.

Sohal, A. S., Keller, A. Z., \& Fouad, R. H. (1988). A review of literature relating to 1IT. International Journal of Operations and Production Management (UK), 9, 15-25.

Spearman, M. L., Woodruff, D. L., \& Hopp, W. J. (1990). CONWIP: a pull alternative to kanban. The International Journal of Production Research. 28(5), 879-894.

So, K. C. (1997). Optimal buffer allocation strategy for minimizing work-in-process inventory in unpaced production lines. IIE transactions, 29(1), 81-88.

Sugimori, Y., Kusunoki, K., Cho, F., \& Uchikawa, S. (1977). Toyota production system and kanban system materialization of just-in-time and respect-for-human system. The International Journal of Production Research, 15(6), 553-564.

Takahashi, K., \& Nakamura, N. (2002). Decentralized reactive Kanban system. European Journal of Operational Research, 139(2), 262-276.

Tardif, V., \& Maaseidvaag, L. (2001). An adaptive approach to controlling kanban systems. European Journal of Operational Research, 132(2), 411-424.

Tayfur A., \& Goang, A. S. (2000) Pull type manufacturing system with multiple product types. IIE Trans, 32, 115-124.

Treleven, M. (1989). A review of the dual resource constrained system research. IIE Transactions, 21(3), 279-287.

Vergara, F. E., Khouja, M., \& Michalewicz, Z. (2002). An evolutionary algorithm for optimizing material flow in supply chains. Computers \& Industrial Engineering, 43(3), 407-421.

Villeda, R., Dudek, R., \& Smith, M. L. (1988). Increasing the production rate of a just-in-time production system with variable operation times. The International Journal of Production Research, 26(11), 1749-1768.

Voss, C. A., \& Robinson, S. J. (1987). Application of just-in-time manufacturing techniques in the United Kingdom. International Journal of Operations \& Production Management, 7(4), 46-52.

Woolsey, R. E., Bowden, R. O., Hall, J. D., \& Hadley, W. H. (1999). A closed-form solution to a kanban sizing problem. Production and Inventory Management Journal, 40, 1-3.

Xiaobo, Z., \& Ohno, K. (1997). Algorithms for sequencing mixed models on an assembly line in a JIT production system. Computers \& Industrial Engineering,32(1), 47-56. 
Yang, K.K. (2000) Managing a flow line with single-Kanban, dual-Kanban or Conwip. Production and Operations Management, 9(4), 349-366.

Yavuz, I. H., \& Satir, A. (1995). A kanban-based simulation study of a mixed model just-in-time manufacturing line. International Journal of Production Research, 33(4), 1027-1048

Yoichi, S., \& Naoto, H. (1999). Transient behavior of single stage kanban system based on the queuing model. International Journal of Production Economics, 60-61, 369-374. 